\title{
Talking Agricultural Sustainability Issues - an Interview with Dr. Gurdev Khush
}

\author{
Gurbir S. Bhullar \\ Swiss Federal Institute of Technology, Zurich, Switzerland
}

Dr. Gurdev Khush is an agricultural scientist well known to the world for his remarkable role in the development of high-yielding rice varieties, which greatly contributed towards ushering a number of countries (particularly in Asia) into the Green Revolution. While leading research at the International Rice Research Institute in the Philippines, as Principal Plant Breeder and Head of the Plant Breeding, Genetics and Biochemistry division, he contributed more than 300 rice varieties including mega-varieties such as IR36, which was planted over 11 million hectares in Asia in the 1980s and attained the status of the most widely planted variety of any food crop. With largescale adoption of these high-yielding varieties, many rice-producing countries attained self-sufficiency in food grain production. Along with honorary doctorates and degrees from twelve universities, his marvelous contribution towards world food security has been honored with many international awards, including the Borlaug Award (1977), Japan Prize (1987), World Food Prize (1996), Wolf Prize for Agriculture (2000), Padma Shri Award - India (2001), and the Golden Sickle Award (2007), to mention a few. He has served as consultant to several national governments and as advisor to a number of institutions and foundations. Besides being an excellent scientist he is a great role model for young scientists. With gratitude to this great personality, I take pleasure in presenting an interview with Dr. Khush for the readers of this book.

Question: Dr. Khush, which scientific issues related to agricultural sustainability concern you most?

Dr. Khush: The most important scientific issues related to agricultural sustainability are depletion of water resources, overuse or misuse of agricultural chemicals, and the expected impacts of climate change on crop productivity, 